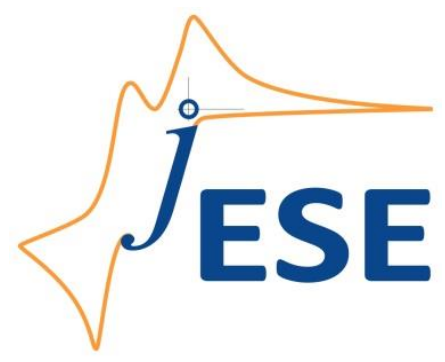

Open Access : : ISSN 1847-9286

www.jESE-online.org

Original scientific paper

\title{
On the stability of platinum-composite electrocatalysts prepared with different substrate materials ${ }^{*}$
}

\author{
Milica G. Košević, Gavrilo M. Šekularac, Vladimir V. Panić ${ }^{\bowtie}$ \\ Institute of Chemistry, Technology and Metallurgy, Department of Electrochemistry, University of \\ Belgrade, Belgrade, Serbia
}

${ }^{\square}$ Corresponding Author: panic@ihtm.bg.ac.rs

Received: February 1, 2016; Accepted: February 4, 2016

\begin{abstract}
Cyclic voltammetry (CV) measurements were conducted and analyzed for a preliminary estimation of the stability of composite electrocatalysts based on Pt. The changes in CV currents of platinum nanoparticles supported on $\mathrm{TiO}_{2}$ were compared to the changes of those supported on commercial carbon. $\mathrm{TiO}_{2}$ was synthesized by sol-gel method and Pt was deposited from Pt colloidal dispersion synthesized by microwave-assisted polyol process. It was found that Pt component in both $\mathrm{Pt} / \mathrm{TiO}_{2}$ and Pt/C behaves similarly with respect to stability and activity during the cycling. The loss in activity with cycling was linear and strongly depended on sweep rate, i.e., the relative loss is higher at lower sweep rates. The steady state activities for both electrocatalysts were reached at the level of $65 \%$ of initial activity and required more than 100 voltammetric cycles.
\end{abstract}

Keywords

Catalytic activity, Metal colloids, Pt supported on $\mathrm{TiO}_{2}$, Sweep rate dependent stability

\section{Introduction}

Fuel cells-related investigations are nowadays in expansion, due to their promising application as alternative energy sources [1,2]. The main focus of current research activities are directed toward fuel cell reliability and durability [1]. Durability of polymer electrolyte membrane (PEM) fuel cell is considerably influenced on the electrocatalytic stability of electrode materials. Hence, a proper selection of nanoarchitecture and composition of membrane electrode assembly (MEA),

\footnotetext{
* Some parts of this work have been presented at $5^{\text {th }}$ Regional Symposium on Electrochemistry - South East Europe (RSE- SEE 5) and awarded as one of the best posters presented.
} 
and particularly the electrode material, is of extreme importance. Electrode material is required to be stable, economically suitable and nonpolluting [3]. Platinum nanoparticles supported on carbonaceous substrates (Pt/C) are widely envisaged as electrocatalysts in fuel cells [4], but carbon suffers from some disadvantages, such as low chemical inertness and modest potential window of stability [5]. Hence, the development of a support alternative to carbon could be of high importance. $\mathrm{TiO}_{2}$ appears to be suitable replacement, because this oxide is of good mechanical and chemical resistance toward acidic and oxidative environments [6]. Pt nanoparticles could be deposited on $\mathrm{TiO}_{2}$ by various methods, e.g., hydrothermal treatment [7,8], photo-assisted reduction [9] and underpotential deposition [10-12]. $\mathrm{TiO}_{2}$ can influence catalytic activity of noble metal, e.g., platinum, due to hypo-d-electron configuration, which can interact with similar configuration of the noble metal [13]. There are studies showing better MEA stability and activity of $\mathrm{Pt}$ nanoparticles supported on mesoporous $\mathrm{TiO}_{2}$ in comparison to commercial carbon as a support [14,15]. However, there are rather opposite findings for the influence of $\mathrm{TiO}_{2}$ to $\mathrm{Pt}$ electrocatalysis; there are papers reporting the improvement for oxygen reduction kinetics $[16,17]$ and the activity in $\mathrm{H}_{2}$ evolution [18], but some results show that $\mathrm{TiO}_{2}$-supported Pt suffers from significantly lower activity in $\mathrm{H}_{2}$ and $\mathrm{O}_{2}$ reactions than Pt supported on carbon [19]. Hence, it could be of interest to take into consideration new approaches in composite catalyst synthesis and more detailed analysis of electrocatalytic properties of synthesized materials, able to mutually produce new findings and benefits for Pt catalysts supported on materials other than carbon of rather modest properties.

The aim of the present work was to synthesize $\mathrm{TiO}_{2}$ as a supporting material for $\mathrm{Pt}$ and to estimate stability and activity of prepared composite at a glance, and to compare these properties with Pt supported on commercial carbon.

\section{Experimental}

$\mathrm{TiO}_{2}$ synthesis. $\mathrm{TiO}_{2}$ was synthesized by forced hydrolysis of $\mathrm{TiCl}_{3} \cdot \mathrm{TiCl}_{3}$ was added dropwise into the boiling $0.7 \mathrm{~mol} \mathrm{dm}{ }^{-3} \mathrm{HCl}$ solution. During $90 \mathrm{~min}$ of boiling under reflux, $\mathrm{TiO}_{2}$ was formed as a fine white precipitate. Obtained precipitate was centrifuged and washed with water, dried and thermally treated at $400^{\circ} \mathrm{C}$ for $3 \mathrm{~h}$ in air, to remove residual chlorides [20].

Pt colloid synthesis. Pt colloid was synthesized by standard polyol process [21]. The mixture of ethylen glycol, which serves as reducing agent for $\mathrm{PtCl}_{6}{ }^{2-}$ and stabilizing agent for produced $\mathrm{Pt}$ particles, and $\mathrm{H}_{2} \mathrm{PtCl}_{6}$ was stirred for $15 \min$. $0.1 \mathrm{M} \mathrm{NaOH}$ was added to increase $\mathrm{pH}$ to 12 and this mixture was placed in microwave at $70 \mathrm{~W}$ for $1 \mathrm{~min}$.

Pt deposition onto $\mathrm{TiO}_{2} / \mathrm{C}$ support from the colloidal dispersion. Pt was deposited onto $\mathrm{TiO}_{2}$, as well as on commercial carbon black (Vulcan XC72R, C) by following procedure. $20 \mathrm{mg}$ of obtained $\mathrm{TiO}_{2}$ powder (or $\mathrm{C}$ ) was ultrasonically dispersed in $20 \mathrm{ml} \mathrm{H} \mathrm{H}_{2} \mathrm{O}$ for $1 \mathrm{~h}$ and transferred into $150 \mathrm{ml}$ of $2 \mathrm{M} \mathrm{H}_{2} \mathrm{SO}_{4}$. The obtained suspension was stirred for $15 \mathrm{~min}$ before Pt colloidal dispersion was added. The stirring was continued for additional $3 \mathrm{~h}$. Upon filtration and rising with water, the obtained $\mathrm{Pt} / \mathrm{TiO}_{2}$ (or $\mathrm{Pt} / \mathrm{C}$ ) composite was thermally treated at $160{ }^{\circ} \mathrm{C}$ in $\mathrm{N}_{2}$ atmosphere. The composite suspension for the preparation of thin layer electrode was formed by ultrasonic treatment $\left(40 \mathrm{kHz}, 70 \mathrm{~W}\right.$ ) of $3 \mathrm{mg}$ of $\mathrm{Pt} / \mathrm{TiO}_{2}(\mathrm{Pt} / \mathrm{C})$ in $1 \mathrm{ml} \mathrm{H} \mathrm{H}_{2} \mathrm{O}$ for $1 \mathrm{~h}$. The suspension was pipetted onto glassy carbon electrode $\left(A=0.196 \mathrm{~cm}^{2}\right)$ and room-dried to form $0.31 \mathrm{mg} \mathrm{cm}^{-2}$ composite thin layer.

Electrochemical measurements were conducted in three-electrode cell using BioLogic SP-200 potentiostat. Saturated calomel electrode (SCE) was used as a reference electrode and platinum 
mesh as a counter electrode in $0.1 \mathrm{M} \mathrm{HClO}_{4}$ electrolyte. All potentials in the paper are given in SCE scale. Before measurements, the cell was deaerated by bubbling the nitrogen for $15 \mathrm{~min}$. Stability of the samples was analyzed as a function of cycling and sweep rate.

Loss of activity was quantified by the relative change of voltammetric charge ( $q / \%)$ in a given cycle with respect to initial one, which has been spent for hydrogen adsorption/desorption processes [22]. The charge was averaged from the data of the well-developed first peak in cathodic direction and its anodic counterpart.

The particle size characterization of the $\mathrm{TiO}_{2}$ was performed by dynamic light scattering (DLS) on Zetasizer Ver. 6.20 instrument Malvern Instruments Ltd., England. The sample for DLS analysis was prepared to mimic the Pt-free mixture for composite synthesis.

\section{Results and discussion}

Figures 1 and 2 show CV curves for $\mathrm{Pt} / \mathrm{TiO}_{2}$ and $\mathrm{Pt} / \mathrm{C}$, respectively, registered in $0.1 \mathrm{M} \mathrm{HClO}_{4}$ at different sweep rates. The $\mathrm{CV}$ currents for both $\mathrm{Pt} / \mathrm{TiO}_{2}$ and $\mathrm{Pt} / \mathrm{C}$ decrease during cycling in a different degree, indicating the continuous loss of the activity. The loss appears differently pronounced in different potential regions and at different sweep rates. In case of $\mathrm{Pt} / \mathrm{TiO}_{2}$ (Fig. 1), the $\mathrm{CV}$ response related to hydrogen adsorption/desorption and oxide formation is better resolved at higher sweep rate (Fig. 1b), which indicates more defined structure of Pt particles more easily accessible to the electrolyte (those located at the outer parts of the composite catalyst layer). The loss of activity upon cycling is more pronounced for $\mathrm{Pt} / \mathrm{TiO}_{2}$ than for $\mathrm{Pt} / \mathrm{C}$ (Fig. 2), although in both cases the substantial loss takes place during the first 50-80 cycles (Figs. 1 a and 2, respectively). In addition, the decrease in $\mathrm{CV}$ currents of $\mathrm{Pt} / \mathrm{TiO}_{2}$ is visible in whole region between potential CV limits (with the smallest decrease related to narrow double region), whereas the oxide formation (up to $0.6 \mathrm{~V}$ ) and reduction in Pt/C appears almost insensitive to the cycling (Fig. 2). Similarly, the oxide reduction region (down to $0.6 \mathrm{~V}$ ) for $\mathrm{Pt} / \mathrm{TiO}_{2}$ negligibly depends on cycling at higher sweep rate (Fig. 1b). If the charge spent for hydrogen adsorption/desorption is taken as a measure of Pt activity (see Experimental), the overall loss of the activity in Fig. $1 \mathrm{a}$ is $35 \%$, which is quite larger than the loss found in Fig. $1 \mathrm{~b}-20 \%$. This indicates also the different structure of outer-layer Pt particles in comparison to those located in most inner, loose parts of composite layer. The corresponding loss for Pt/C is a bit lower (Fig. 2), $12 \%$, although the number of cycles spent is considerably lower. Hence, it could be stated that $\mathrm{Pt} / \mathrm{TiO}_{2}$ and $\mathrm{Pt} / \mathrm{C}$ are of similar characteristics upon cycling at higher sweep rates, or that outer-layer $\mathrm{Pt}$ in $\mathrm{Pt} / \mathrm{TiO}_{2}$ reaches the finely tuned structure upon ca. 150 cycles.

Although the two composite catalysts are prepared by the same procedure, the CV currents of $\mathrm{Pt} / \mathrm{TiO}_{2}$ are considerably lower than those of $\mathrm{Pt} / \mathrm{C}$. The $\mathrm{Pt}$ loading was projected to 20 mass \%. According to the $\mathrm{Pt} / \mathrm{C} \mathrm{CV}$ response, the $\mathrm{Pt}$ nanoparticles diameter, calculated on the basis of standard procedure [21], is around $7 \mathrm{~nm}$. In order to check Pt loading in $\mathrm{Pt} / \mathrm{TiO}_{2}$ composite, spectrophotometric measurements were employed. In this procedure, composite was dissolved in the aqua regia and obtained solutions were analyzed on the UV-Vis spectrophotometer and compared to the standards. It was found that Pt loading is almost the same as in the Pt/C composite, i.e. 19 mass \%. However, the calculation of $\mathrm{Pt}$ content from $\mathrm{Pt} / \mathrm{TiO}_{2} \mathrm{CV}$ response returns the value of $c a .3$ mass \%, with the assumption that Pt particles of similar size are formed in $\mathrm{Pt} / \mathrm{TiO}_{2}$ and $\mathrm{Pt} / \mathrm{C}$ due to identical preparation procedure. It follows that considerable amount of $\mathrm{Pt}$ in $\mathrm{Pt} / \mathrm{TiO}_{2}$ is not involved in $\mathrm{CV}$ response. This could be due to semiconductive nature of $\mathrm{TiO}_{2}$. 
Namely, if there are some distinct heaps of $\mathrm{Pt}$ particles on $\mathrm{TiO}_{2}$ surface, there will not be conductive pathways toward external circuit as it is in the case carbon support.

(a)

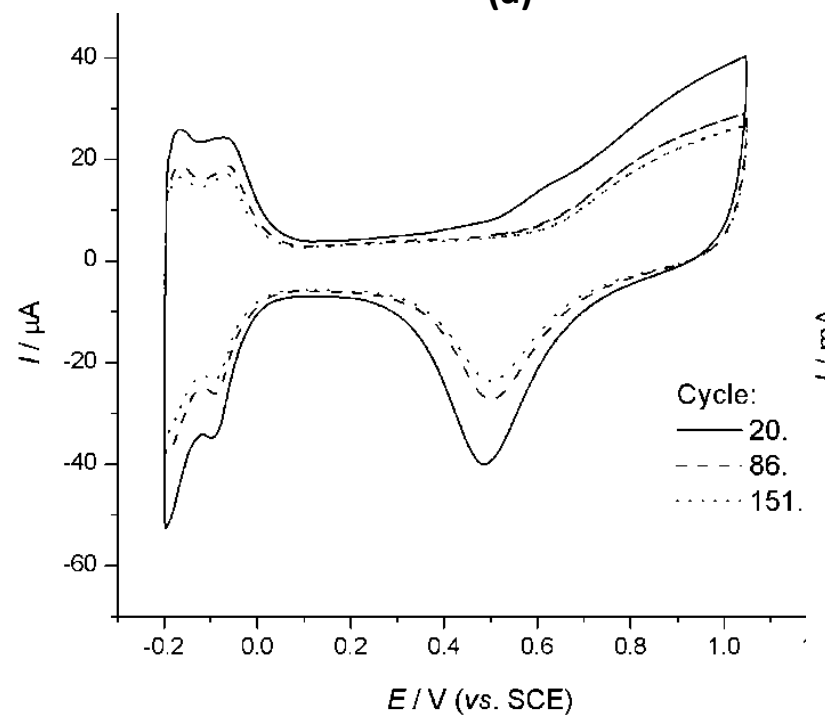

(b)

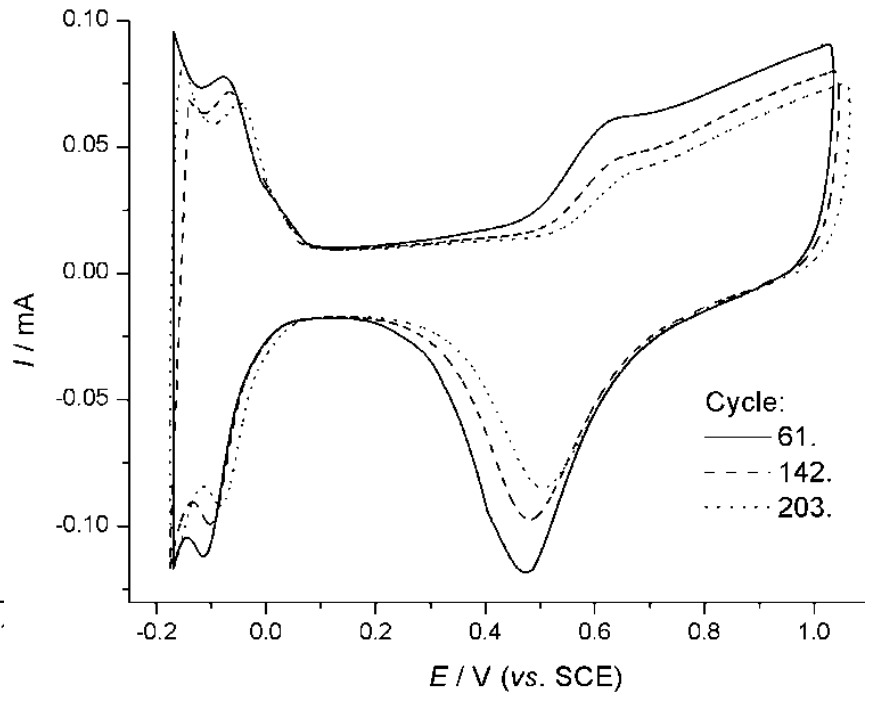

Figure 1. Characteristic cyclic voltammograms of Pt supported on $\mathrm{TiO}_{2}$ at sweep rates of 50 (a) and $200 \mathrm{mV} \mathrm{s}^{-1}(\mathrm{~b})$, registered during continuous cycling in deaerated $0.1 \mathrm{M} \mathrm{HClO}_{4}$.

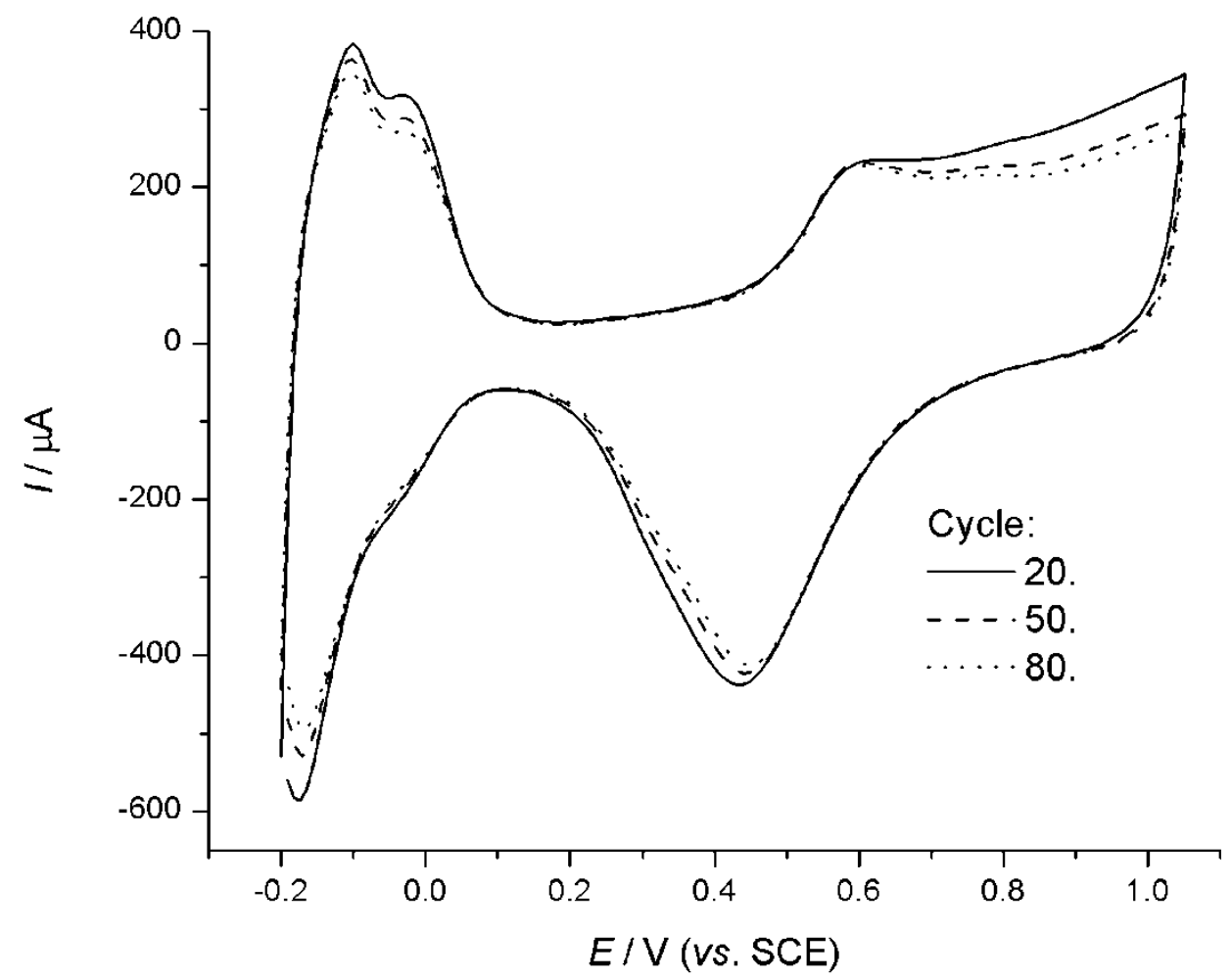

Figure 2. Characteristic cyclic voltammograms of Pt supported on $C$, registered during continuous cycling in deaerated $0.1 \mathrm{M} \mathrm{HClO}_{4}$ at sweep rate of $100 \mathrm{mV} \mathrm{s}^{-1}$.

In order to check possible morphological relationships between $\mathrm{Pt}$ and $\mathrm{TiO}_{2}$, particle size distribution (PSD) of the $\mathrm{TiO}_{2}$ powder suspended in the medium for Pt deposition was analyzed by dynamic light scattering (DLS). Figure 3 shows the registered PSD averaged on ten successive runs expressed as distributions by intensity and volume. DLS registers the particles of $c a .400 \mathrm{~nm}$ and agglomerates of $c a$. 2.5-3 $\mu \mathrm{m}$. The material appears mainly concentrated in agglomerates since the distribution by volume is considerably larger. On the other hand, the number of particles and 
agglomerates are comparable since the distribution by intensity is similar (10 and $8 \%$, respectively).

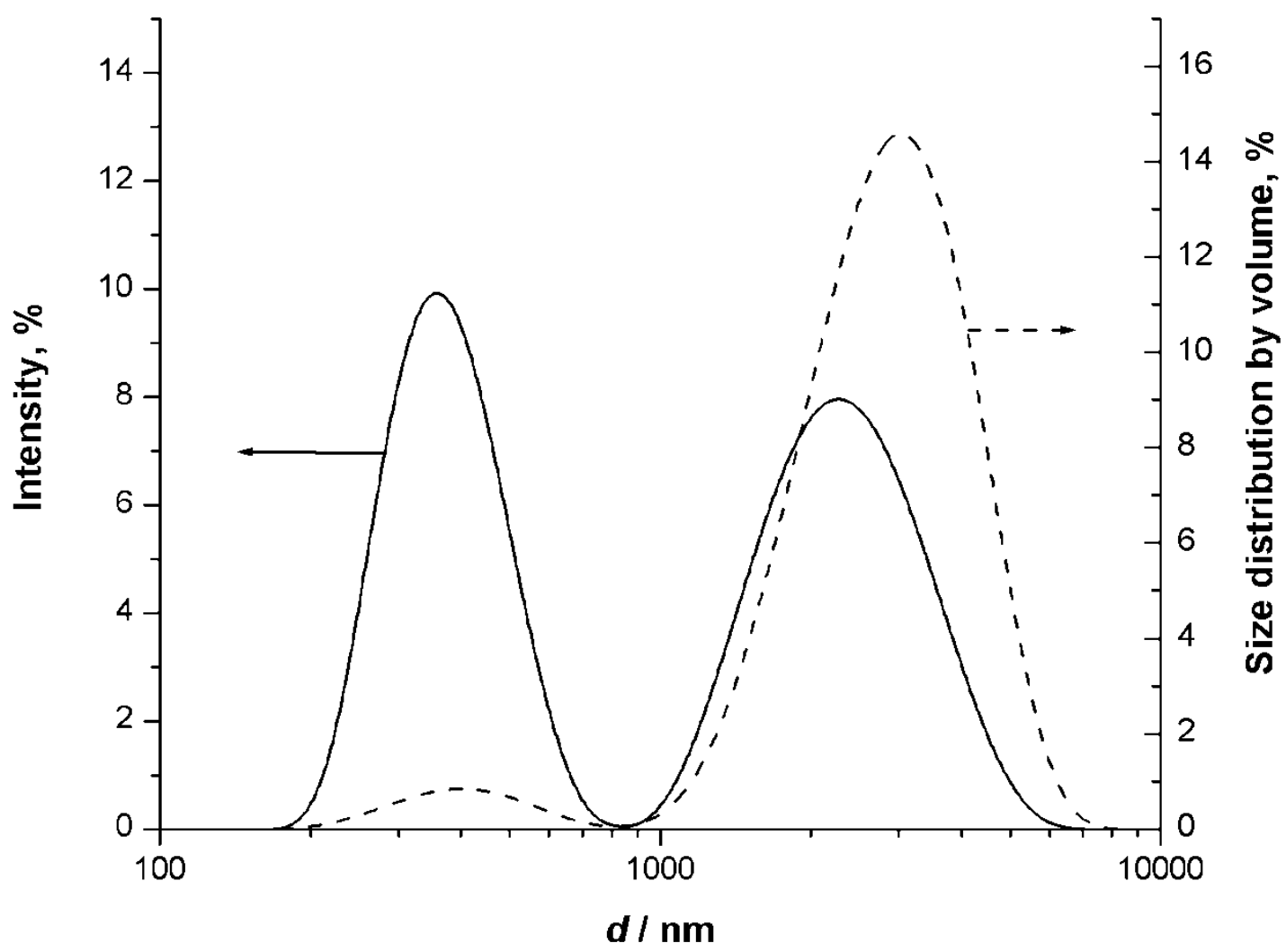

Fig. 3. Particle size distribution by dynamic light scattering of $\mathrm{TiO}_{2}$ solid phase in the medium for Pt deposition.

If $400 \mathrm{~nm}$-sized $\mathrm{TiO}_{2}$ particles would be considered as a support to host $7 \mathrm{~nm}$-sized Pt particles (both ideally spherical), the monolayer of Pt particles could produce around 30 mass \% of Pt, fairly above projected value. This indicates that the size of $\mathrm{TiO}_{2}$ and $\mathrm{Pt}$ particles are optimal for the production of composite catalyst with desired Pt content. On the other hand, $3 \mu \mathrm{m}$-sized $\mathrm{TiO}_{2}$ agglomerates are able to accommodate 4.5 mas. \% of Pt in full particle monolayer. It could be that pronounced agglomeration as seen in Fig. 3 causes the Pt hosted by $400 \mathrm{~nm}$-sized $\mathrm{TiO}_{2}$ to be trapped within agglomerates and hence not available for CV response. Consequently, those Pt particles on the surface of agglomerates are able in a high degree to create connection pathways toward GC substrate, and produce a CV response corresponding to few mass \% as obtained from Fig. 1.

Loss of activity, quantified by the voltammetric charge related to hydrogen adsorption/desorption, can be additionally analyzed as a function of a cycling and applied sweep rate. The relative changes in charge, i.e., catalyst activity, is presented in Fig. 4. $\mathrm{Pt} / \mathrm{TiO}_{2}$ loses $10-13 \%$ of initial activity in first 40 cycles, which appears only slightly dependent on sweep rate. The initial decrease of $c a .8 \%$ is registered at $50 \mathrm{mV} \mathrm{s}^{-1}$, whereas additional 20 cycles at $200 \mathrm{mV} \mathrm{s}^{-1}$ produces further loss of $c a .5 \%$. This slowing down of the loss by the increase in sweep rate indicate that related transformations of Pt particles are sweep rate-dependent. It could be that the transformations are of more pronounced reversibility at higher sweep rates (e.g., reverse coarsening) [22] or that Pt particles from the inner part of a layer reach the final state of transformations much easier than the particles from the outer part of a layer. These effects could cause also the differences in CV responses from Fig. $1 a$ and $b$, in which the hydrogen adsorption/desorption region is less pronounced at lower (Fig. 1a) than at higher sweep rate (Fig. 1b). 


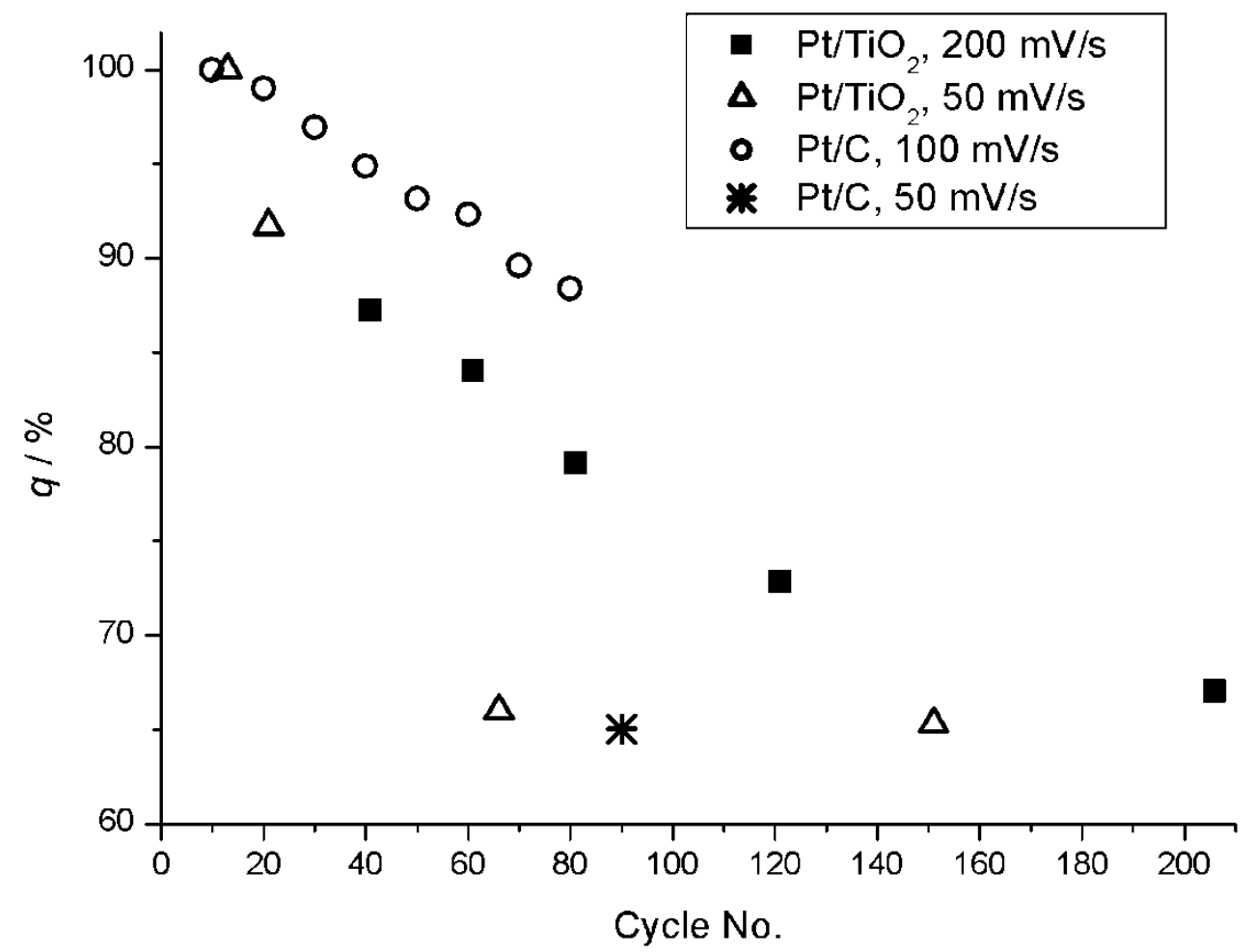

Figure 4. The relative changes in voltammetric charge of hydrogen adsorption/desorption for $\mathrm{Pt} / \mathrm{TiO}_{2}$ and $\mathrm{Pt} / \mathrm{C}$ during the cycling.

In order to check the validity of the differences in charge at different sweep rate, the CV responses at 50 and $200 \mathrm{mV} \mathrm{s}^{-1}$ are compared after 60th and 150th cycle. Indeed, the loss of the activity at $50 \mathrm{mV} \mathrm{s}^{-1}$ is more than twice of that registered at $200 \mathrm{mV} \mathrm{s}^{-1}$ after 60 cycles. As the Pt reaches the stable transformation state during next $60-90$ cycles at $200 \mathrm{mV} \mathrm{s}^{-1}$, this difference becomes considerably less pronounced (the losses of activity at 50 and $200 \mathrm{mV} \mathrm{s}^{-1}$ are c.a. 35 and $28 \%$, respectively). In addition, this feature is checked also for Pt/C after 80 cycles; the result is similar and even more pronouncedthan for $\mathrm{Pt} / \mathrm{TiO}_{2}$ : around $12 \%$ loss at $100 \mathrm{mV} \mathrm{s}$ and $35 \%$ at $50 \mathrm{mV} \mathrm{s}^{-1}$. These findings are in fair accordance to the suppositions of sweep rate-sensitive reversed transformations and their rate distribution throughout composite layer.

The reported results indicate that $\mathrm{Pt}$ component in both $\mathrm{Pt} / \mathrm{TiO}{ }_{2}$ and $\mathrm{Pt} / \mathrm{C}$ behaves similarly with respect to stability and activity during the cycling. The loss of activity is linear upon cycling and appears strongly dependent on sweep rate. The steady state transformations of $\mathrm{Pt}$ is reached at the level of $65 \%$ of activity with respect to initial state and require more than 100 voltammetric cycles. This behavior appears related to sweep rate-dependent reverse transformations, probably coarsening, and distribution of such transformations through the composite layer in a way that Pt particles from inner part of a layer are transformed much easier and faster.

\section{Conclusion}

Electrocatalytic activity and stability of $\mathrm{Pt}$ supported on $\mathrm{TiO}_{2}$ and $\mathrm{C}$ were examined and compared on the basis of routine cyclic voltammetry measurements at various sweep rates. Platinum was synthesized by polyol process and deposited on sol-gel synthesized $\mathrm{TiO}_{2}$ and commercial carbon. The loss of activity of Pt particles was quantified by the voltammetric charge related to hydrogen adsorption/desorption. The results showed that the Pt particles behave in similar manner for two different supporting materials. Steady state activities were reached after 100 cycles, when activity decreased by $35 \%$ with the respect to the initial activity. The loss of 
activity is strongly dependent on sweep rate and tends to be higher at lower sweep rates. This is probably due to less reversible Pt particles transformations at lower sweep rates, including agglomeration and coarsening.

Acknowledgement: This work was financially supported by the Ministry of Education, Science and Technological development of the Republic of Serbia. The authors thank Sanja Stevanovic and Dušan Tripković of the Institute of Chemistry, Technology and Metallurgy, University of Belgrade, for a fruitful assistance in collecting the data related to the cyclic voltammetry behavior of Pt/C catalyst.

\section{Literature:}

[1] Y. Shao, G. Yin, Y. I. Gao, Journal of Power Sources 171 (2007) 558-566

[2] A. B. Stambouli, E. Traversa, Renewable and Sustainable Energy Reviews 6 (2002) 297-306

[3] S. Hadži Jordanov, P. Paunović, O. Popovski, A. Dimitrov, D. Slavkov, Bulletin of the Chemists and Technologists of Macedonia 23 (2004) 101-112

[4] S. Zhang, X-Zi Yuan, J. N. C. Hin, H. Wang, K. A. Friedrich, M. Schulze, Journal of Power Sources 194 (2009) 588-600

[5] D. S. Kim, E. F. A. Zeid, Y.T. Kim, Electrochimica Acta 55 (2010) 3628-3633

[6] Z. Liu, J. Zhang, B. Han, J. Du, T. Mu, Y. Wang, Z. Sun, Microporous and Mesoporous Materials 81 (2005) 169-174

[7] J. Yu, L. Qi, M. Jaroniec, Journal of Physical Chemistry C 114 (2010) 13118-13125

[8] S. C. Colindres, J. R. V. García, J. A. T. Antonio, C. A. Chavez, Journal of Alloys and Compounds 483 (2009) 406-409

[9] H. Schulz, L. Mädler, R. Strobel, R. Jossen, S. E. Pratsinis, T. Johannessen, Journal of Materials Research 20 (2005) 2568-2577

[10] S. Gan, Y. Liang, D. R. Baer, M. R. Sievers, G. S. Herman, C. H. F. Peden, Journal of Physical Chemistry B 105 (2001) 2412-2416

[11] B. Sun, A. V. Vorontsov, P. G. Smirniotis, Langmuir 19 (2003) 3151-3156

[12] J.-M. Herrmann, J. Disdier, P. Pichat, The Journal of Physical Chemistry 90 (1986) 60286034

[13] N. Rajalakshmi, N. Lakshmi, K.S. Dhathathreyan, International Journal of Hydrogen Energy 33 (2008) 7521-7526

[14] Y. P. G. Chua, G. T. K. K. Gunasooriya, M. Saeys, E. G. Seebauer, Journal of Catalysis 311 (2014) $306-313$

[15] G. P. López, R. R. López, T. Viveros, Catalysis Today 220-222 (2014) 61-65

[16] A. Bauer, K. Lee, C.J. Song, Y.S. Xie, J.J. Zhang, R. Hui, Journal of Power Sources 195 (2010) 3105- 3110

[17] B. Hammer, J.K. Norskov, Advances in Catalysis 45 (2000) 71-129

[18] Q. Du, J. Wu, H. Yang, ACS Catalysis 4 (2014) 144-151

[19] H. Zhao, Y. Wang, Q. Tang, L. Wang, H. Zhang, C. Quan, Tao Q, International journal of hydrogen energy 39 (2014) 9621-9627

[20] J. Croy, S. Mostafa, J. Liu, Y. Sohn, B. R. Cuenya, Catalysis Letters 118 (2007) 1-7.

[21] X. X. Wang, Z. H. Tan, M. Zeng, J. N. Wang, Scentific Reports 4 (2014) 4437

[22] A. Pozio, M. De Francesco, A. Cemmi, F. Cardellini, L. Giorgi, Journal of Power Sources 105 (2002) 13-19

[23] M. S. Bootharaju, V. M. Burlakov, T. M. D. Besong, C. P. Joshi, L. G. AbdulHalim, D. M. Black, R. L. Whetten, A. Goriely, O. M. Bakr, Chemistry of Materails 27 (2015) 4289-4297

(C) 2016 by the authors; licensee IAPC, Zagreb, Croatia. This article is an open-access article distributed under the terms and conditions of the Creative Commons Attribution license

(http://creativecommons.org/licenses/by/4.0/) 